\title{
FLORES DA CEREJEIRA E DA PAINEIRA (PAISAGENS)
}

\author{
THE CHERRY BLOSSOM AND THE PAINEIRA (LANDSCAPES)
}

\begin{abstract}
SANDEVILLE JR., Euler
Arquiteto e Urbanista (PUC.Camp, 1981), Arte-Educador (FEBASP, 1983), Mestre e Doutor em Estruturas Ambientais Urbanas (FAU.USP, 1994, 1999), Pós-Graduação em Ecologia (USJT, 1996). Professor dos cursos de graduação e pós-graduação da Faculdade de Arquitetura e Urbanismo da USP e do Programa de PósGraduação em Ciência Ambiental da USP PROCAM, coordenador da Área de Concentração Paisagem e Ambiente e Coordenador do Laboratório Gestão e Projeto do Espaço (FAU.USP). sites: http://www.ambiente. arq.br e http://www.linguagens.art.br
\end{abstract}

HIJIOKA, Akemi

Arquiteta Urbanista (UBC, 1992), Mestrando em Urbanismo (PUC Campinas, 2005 - em curso)

\section{RESUMO}

Este trabalho explora o significado e a constituição da palavra paisagem no japonês e no português, procurando recuperar aspectos abandonados por uma excessiva valorização da paisagem como visualidade, forma ou representação. Coloca como fundamentais a essa reconstituição necessária de significados e sensibilidades, o sentido da paisagem enquanto vivência e experiência.

\section{Palavras-chave: Paisagem, ambiente, natureza, cultura.}

\section{ABSTRACT}

This work explores the meaning and the constitution of the word landscape in Japanese and in Portuguese, trying to recover aspects that were abandoned due to the over evaluation of landscape in its visual sense, in its forms or its representation. The proposed reconstitution of meanings and sensibilities is based on an understanding of landscape as an experience.

Key words: Landscape, environment, nature, culture.

\begin{abstract}
"Antes de poder ser um repouso para os sentidos, a paisagem é obra da mente. Compõe-se tanto de camadas de lembranças quanto de estratos de rochas" Simon SCHAMA (1996:17).

"(...) em se tratando de paisagem, ainda que possua uma forma material, ela tende ao espiritual" Zong Bing (375-443)'.
\end{abstract}

Segundo o "Dicionário Aurélio" (FERREIRA, s/d), paisagem é um "espaço de terreno que se abrange num lance de vista; pintura, gravura, desenho que representa uma paisagem natural ou urbana". O dicionário LONGMAN (1998) define landscape como "a wide view of country scenery". Talvez essa polaridade entre espaço e sua visualidade indiquem bem a natureza do problema. O sentido coloquial da palavra é muito forte, dificultando sua adoção como conceito, ao guardar uma necessária ambigüidade entre "espaço de terreno" (realidade geográfica) e "lance de vista" (percepção). No uso coloquial é priorizado o entendimento da paisagem como a própria imagem (figura) construída na percepção do observador. Com isso seu significado conceitual pode resultar minimizado. Um segundo problema é que se torna fácil confundir essa imagem com a representação plástica de uma cena, registrada em uma pintura ou fotografia, o que acarreta, em nosso entendimento, na limitação da percepção da paisagem e no seu entendimento enquanto campo de investigação e atuação. 
SANDEVILLE JR. (1999, 2004, 2006 no prelo) tem argumentado que esse sentido coloquial é insuficiente para dar conta da paisagem, mas tem sido adotado como base parcial de esforços de conceituação, gerando uma ênfase em seus aspectos morfológicos, minimizando os conteúdos culturais (MENEZES 2002) pelos quais a paisagem é, como sugerimos, além de forma e representação, uma "experiência partilhada" (SANDEVILLE JR. 2004, no prelo). Temos utilizado uma compreensão da etimologia da palavra, que aponta para uma necessária pesquisa de caráter histórico ainda apenas indicada, a fim de renovar a associação de sentidos que de imediato a palavra possa sugerir a estudiosos dos fenômenos espaciais e culturais. Neste artigo, avançaremos pela constituição da palavra paisagem no japonês e no português, procurando mostrar que o campo a que se refere e que representa, embora inclua a percepção visual e o estudo morfológico, os ultrapassa em muito. Significados e sentidos sem os quais os estudos de paisagem podem cair presas de um formalismo e de uma objetividade superficial que ignoram, de fato, o que seja a paisagem.

景

"La diferencia entre las actitudes europea y china en cuanto el arte es acentuada por el comentario de Roger Fry: 'Uno siente que debe ponerse un poco en guardia sobre un pueblo que invento la ceremonia del té, un pueblo que hipnotiza a sí mismo en una actitud de expectante adoración estética. Ellos dirían, sin duda, que esta ocupación hipnótica de caminar a lo largo del paseo del jardín en silencio hasta la casa de té, únicamente servía para producir una adecuada receptividad para disponerle a uno a una actitud favorable. Pues esto es precisamente: ellos están siempre disponiéndole a uno a una actitud demasiado favorable, quitándole a uno mediante la hipnosis su sentido común crítico. Tienen una manera astuta de hacer que las cosas parezcan preciosas aun antes de que se hayan preparado y ostentarlas con exquisito gusto" Segundo CLIFFORD (1970:178).

No Japão, a palavra paisagem 気色 (keshiki), foi introduzida da China (qisè em chinês) ${ }^{2}$, formada pelo kanji 気 (ki) significando força vital e absoluta base de todo o ser, e pelo kanji 色 (shiki), significando cor. Segundo a enciclopédia Ni-Chu-Ei Guengo Bunka Jiten (ASSANO 2000), o significado de keshiki escrito com esses kanjis inclui além do mundo natural a expressão humana: feição, atitude, idéia, sentimento. Mas no século XVII (período Edo) passou-se a escrever com o kanii kei (景), e keshiki passou a ser utilizado para referir-se ao aspecto do mundo externo neutralizando a conotação de subjetividade, uma vez que existem várias outras palavras para referir-se a outros aspectos. É hoje de uso corrente no Japão a palavra introduzida do inglês ンドスケープ (randosukeepu), do inglês landscape.

O sentido básico trazido por kei (景) para as diversas designações de paisagem no japonês é o de meio, referindo-se tanto à situação (no tempo e no espaço), visualidade e sensação, mas seu significado se completa somente quando associado a um outro kanji. Localizamos para este artigo mais de trinta palavras derivadas do kei (景). Muitas delas podem ser usadas tanto para representar formas visuais da paisagem como para descrever situações. Seu sentido figurado aparece freqüentemente dependendo do contexto em que é utilizado. Trata-se de um ideograma picto-fonético: onde a parte semântica日 (hi) significa sol, e a parte fonética京 (kyo, kei), que define a pronúncia, traz a idéia de posição, significando cidade principal, tal como é usado para muitas cidades como Tōkyo (東京) e Pekim (北京). Juntos日 (hi) e 京 (kyo, kei), formam um novo kanji, cujo significado não se constrói por adição, mas estabelece uma nova idéia e uma nova sensação.

Quando se lê um kanji já se sabe imediatamente de que se trata, no sentido de uma idéia e um sentimento, de um conceito inerente ao kanji exceto quando modificado pela adição a outro para formar outra palavra. No japonês existem mais de trinta formas para designar os aspectos da chuva, revelando uma atenção em captar todas as nuances que uma situação pode suscitar na integração com o meio ${ }^{3}$. É diferente do alfabeto ocidental, onde cada signo corresponde a 
um som. Conforme a situação um kanji pode ter sons diferentes, significando coisas diferentes. O kanji não é, portanto, uma letra, mas uma idéia, uma representação visual que inclui uma dimensão afetiva e simbólica (como se pode exemplificar no próprio processo de constituição do ideograma, figura 1).
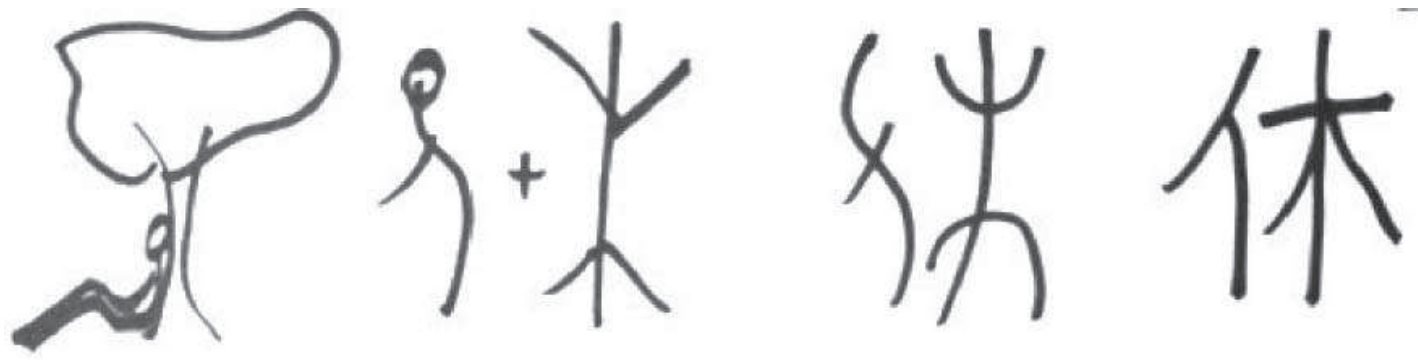

Figura 1: Ideograma de descansar (yasumu: 休む): pessoa (hito: 人) + árvore (ki: 木)

Há uma composição a partir de ideogramas básicos (como em keshiki: 気十色, 景十色), que mudam o sentido constituindo um novo, que se refere a um conceito e a uma sensação que se espera exprimir. Não se trata, portanto, de uma adição de dois significados (como no inglês land+scape, sea+scape) para formar uma outra palavra, mas que cada palavra através dos kanjis que a formam abriga em si o conceito, a sensação, a sensibilidade e uma forma de vivência. A construção da palavra seascape, landscape etc., não tem como intrínseca essa matização e refinamento expressivo de emoções e significados. A composição com outro kanji forma uma palavra que representa aspectos pluridimensionais e multisensoriais, que são captados como inerentes na leitura.

Um exemplo pode ser dado para elucidar essa forma de pensar: a palavra dakishimeru (抱し める), pode ser traduzida genericamente por abraço. Porém, ao perguntarmos a um japonês o significado da palavra, freqüentemente a tradução virá acompanhada de uma expressão sensível e introspectiva do gesto de um abraço terno, sensação e afeição tão parte do kanji quanto o significado. Desta forma, os ideogramas que poderíamos traduzir por paisagem expressam formas diversas de vivência com a paisagem. Abaixo apresentamos algumas das palavras que conseguimos identificar que podem ser empregadas com a significação de paisagem.

1. Bankei (晚景) - paisagem ao anoitecer. Ban (晚) noite, kei (景).

2. Bankei (盤景) - paisagem reconstituída com pedras, areias, musgos em um vaso ou bandeja. Ban (盤) prato, kei (景).

3. Bikei (美景)-paisagem bela. Bi (美) beleza, kei (景).

4. Bonkei (盆景) - paisagem transferida em menor escala, normalmente miniaturizada em vasos. Bon (盆) vaso, bandeja, kei ( 景).

5. Enkei (煙景) - paisagem esfumaçada. En (煙) fumaça, kei (景)

6. Enkei (遠景) - paisagem distante. Em (遠) longe, kei (景).

7. Fukei (風景) - aspecto visual de uma paisagem ou sensação perante uma situação. Fu (風) vento (景) lugar ou situação resultante da conformação da natureza, pessoas, construções ou ações.

8. Fukou (風光) - expressão formal de representação da paisagem sublime. Fuu (風) vento, kou (光) luz.

9. Gokei (後景 ) - paisagem que se encontra na parte posterior. Go (後) atrás, kei (景).

10. Haikei (背景) - paisagem de fundo, pano de fundo, visual ou situação que faz o fundo na presença de uma figura principal ou situação principal. Hai (背) costas.

11. Jikkei (実景) - paisagem ou fato real. Jitsu (実) real, kei (景).

12. Joukei (場景) - paisagem específica no qual ocorreu um fato. Jou (場) lugar, kei (景). 
13. Joukei (情景) - situação que provoca emoção ao espectador. Emoção sentida por coisa ou situação. Jou (情) emoção, kei (景).

14. Kaikei (海景) - paisagem do mar. Kai (海) mar, kei (景).

15. Keikan (景観) - visual, vista, aparência de um local ou situação. Kei (景), Kan (観) visual.

16. Keiki (景気) - sensação que o ambiente causa, denota aspecto da fruição de uma situação econômica ou relação. Kei (景) ambiente, ki (気) ânimo.

17. Kinkei (近景) - paisagem próxima. Kim (近) perto.

18. Koukei (好景) - paisagem particularmente agradável. Kou (好) gostar, kei (景).

19. Koukei (光景) - aspecto emocional de um visual ou uma situação. Kou (光) luz + Kei

(景).

20. Sekkei (雪景) - paisagem da neve. Setsu (雪) neve, kei (景).

21. Shakei (借景) - paisagem em empréstimo, sha (借) emprestar, expressão usada principalmente na era meiji (1868-1912) no paisagismo oriental, anteriormente era usada a expressão Ikedori que significava trazer vivo, internalizar o mundo externo, na prática seriam aberturas estratégicas na edificação para trazer o espaço externo para dentro, com fins de apreciação da paisagem e sua diversidade de transformações trazidas pelas estações.

22. Shakei (斜景) - paisagem inclinada (trata se da apreensão da sombra, quando esta se destaca, evidencia e predomina na leitura), ou a representação figurada de um idoso. Sha (斜) inclinação, kei (景).

23. Shinkei (真景 ) - paisagem verdadeira (quando comparada a paisagem pintada, trata se daquela que serviu de inspiração). Shiin (真) verde, kei (景).

24. Shoukei (小景 ) - paisagem singela, pequena. Shou (小) pequena, kei (景).

25. Shunkei (春景) - paisagem da primavera. Shun (春) primavera, kei (景).

26. Shuukei (修景) - paisagem de conformada. Shuu (修) conformar, kei (景).

27. Sokei (祖景) - paisagem simples, rústica, sem elaboração. So (祖) rústica + Kei (景).

28. Yakei (夜景) - paisagem noturna. Ya (夜) noite, kei (景).

29. Yuukei (夕景) - paisagem da tarde. Yuu (夕) entardecer, kei (景).

30. Zekkei (絶景) - paisagem sem igual, absoluto. Zetsu (絶) único, kei (景).

31. Zenkei (全景) - paisagem total. Zen (全) tudo, kei (景).

32. Zenkei (前景) - paisagem que se encontra na parte fontal. Zen (前) frente, kei (景).

O trajeto entre o objeto e a subjetividade ${ }^{4}$, isto é, o que está sendo vivenciado (seja de forma visual ou emocional), e como se processa essa vivência, é que define a palavra a ser empregada. É nesse percurso entre objetividade e subjetividade que se dá a sensação, o tempo, o lugar, o conjunto de possibilidades e significados mobilizados. A apreensão da paisagem, portanto, resulta de um processo onde a dinâmica é determinante da palavra escolhida, revelando um conjunto de possibilidades de percepção que vão muito além da imagem, da visualidade e da forma.

Nos cumpre agora questionar a que universos a palavra portuguesa paisagem poderia estar remetendo. De que idéias e que sensibilidades é portadora e veicula? Que potencial essa palavra - paisagem - nos permite mobilizar e o que podemos aprender dessas construções ocidentais e orientais para compreender a natureza do objeto de estudo paisagem? Que implicações deveriam e poderiam ser mobilizadas e contempladas para que os estudos da paisagem se refiram efetivamente aos conteúdos e possibilidades que abriga?

\section{País ${ }^{5}$}

A palavra paisagem nos veio do francês, paysage (derivando de pays = país, região, território, pátria etc.), palavra "surgida" (atestada seria melhor) nessa língua, segundo o dicionário Robert, em 1549 (segundo informa POLETTE, 1999) e no português nos séculos 16 e 17: paugage (século 
16) e paizagem em 1656 (segundo CUNHA 1982). Neste último autor (1982:572) encontramos o verbete: "país sm. 'região, território, nação' XVII. Do fr. pays deriv. do b. lat. page(n)sis, do lat. pagus (V. PAGO) // paisAGEM / XVI, paugagê XVI, paizagem 1656 etc. / Do fr. paysage // paisAG.ISMO XX // paisAC.ISTA 1844. Do fr. paysagiste // paisANO / paysano XVII / Do fr. paysan // paisEIRO XX". Já o sufixo agem teria origens distintas (CUNHA 1982), derivando do latim ago, aginis "com as noções de estado, situação, ação, ou resultado da ação" ou do francês age que derivou do latim aticum.

Como se nota, a palavra deriva de país, que se refere não apenas ao espaço físico, mas a uma apropriação peculiar do espaço, à construção de um território e de um povo, para então se tornar, talvez, a imagem desse território. Todas as palavras - país, paisagem - remetem a um forte conteúdo cultural, associando espaço e representação: lugar, território, cultura, imaginação. É desse universo de significação que emerge, secundariamente, o sentido de forma e aparência. Aparência de um conteúdo, a "alma do lugar", do pitoresco, da construção de um lugar social, mesmo quando a idéia de natureza se torna determinante, cuja estetização coloca, em primeiro plano, a forma das coisas, cujo arranjo passa a ser visto como paisagem.

Nas línguas latinas pais(AGEM) tem origem no latim pagus (marco ou baliza metida na terra, território rural delimitado por marcos, distrito, aldeia, povoação). Dessa palavra derivam outras como paganalia (festas de aldeia), paganicus (de aldeia, do campo, camponês, aldeão, pagão, civil, paisano). Convém mencionar que pagus tem raiz em pag (= fixar, plantar, pregar, estabelecer, convencionar), de onde também vem a palavra pax (= resolver por acordo entre as partes, ausência de guerra, indulgência, favor, concórdia). No grego encontramos palavra semelhante, pagos, significando coisa fixa, planície, montanha.

A origem da palavra (pagus) implica, portanto, no conceito de território delimitado, distrito, sendo seu principal sentido o de localidade, aldeia (para campo temos a palavra ager: campo, terra cultivada, pomar etc., da qual derivam agricultura e agrestis, isto é, dos campos, relativo aos campos, rústico, silvestre, selvagem, coisas que hoje ninguém pensaria em não incluir na noção abrangida pela palavra paisagem). Ao que foi possível apurar, PAISagem trata-se de uma invenção moderna6. SANDEVILLE JR. (2006, no prelo) aponta a necessidade de um aprofundamento da investigação por esse viés, na medida em que, etimologicamente, a origem da palavra no francês e no português, situa-se em torno aos séculos 16 e 17, isto é, no período designado habitualmente por Renascença e Barroco, de afirmação dos Estados Nacionais e sua expansão colonial. A palavra poderia ter surgido para designar uma nova percepção possível, ainda que logo absorvida na fruição estética que reordenava esse mundo, e a capacidade de apreciá-lo e controlá-lo.

O sentido veiculado na argumentação que apresentamos remete claramente à territorialidade, com uma inerente natureza cultural e a dimensão sensível implicada. Daí é insuficiente definir o "objeto de conhecimento" paisagem com base exclusivamente em sua percepção visual (a qual, para nós, ficaria melhor compreendida como panorama, prospecto ${ }^{7}$ ). A redução da paisagem à sua mera visibilidade formal aproxima sua compreensão da idéia de pitoresco, o "pinturesco": aquilo próprio para ser pintado, a cena (embora o pitoresco esteja muito além desse sentido). Reduzida a cenário, facilmente resvala para o decorativo, o superficial, o acessório, revelando alguns dos problemas de enfrentamento da paisagem em nossa sociedade.

O que, de imediato, poderíamos tirar do que foi exposto? Antes de qualquer coisa, o fato das paisagens terem significados, certos sabores característicos e culturais, que lhe são indissociáveis, e frutos da interação de múltiplos processos imbricados que a constituem como tal. Postulamos que o entendimento da paisagem apenas como forma ${ }^{8}$ não é capaz de dotar-lhe dessa vida, arriscando convergir num registro que não lhe toca o essencial: a natureza processual e vivencial implicada pela idéia de paisagem. A paisagem, mais do que espaço observado, trata-se de espaço vivenciado, da sensibilidade das pessoas com seu entorno?. 
LÉVI-STRAUSS (1993:50), em Tristes Trópicos, usou a paisagem como uma metáfora do conhecimento. Em suas excursões no Languedoc, perseguindo ao longo do flanco de planalto calcário a linha de contato entre duas camadas geológicas observava que "essa linha tênue e confusa, essa diferença por vezes imperceptível de forma e consistência dos resíduos rochosos, testemunha que, ali onde hoje vejo um terreno árido, se sucederam outrora dois oceanos". Restaria ainda inserir o homem nessa "deambulação" pela paisagem e pelo conhecimento, e reconhecer, com Simom SCHAMA (1996:17), que "conquanto estejamos habituados a situar a natureza e a percepção [poderíamos dizer também a cultura] humana em dois campos distintos, na verdade elas são inseparáveis. Antes de poder ser um repouso para os sentidos, a paisagem é obra da mente. Compõe-se tanto de camadas de lembranças quanto de estratos de rochas".

\author{
綿の木の \\ 花のさかりは \\ さながらに \\ 故国の桜の \\ 花を思わしむ 12 \\ IWANAMI1993:37
}

\title{
Notas
}

(1) Citado por Berque 2000:44

(2) Segundo Augustin BERQUE (2000:44), o primeiro tratado da paisagem da humanidade data do século V, quando Zong Bing (375-443), escreveu a "Introdução à pintura da paisagem", no qual se pode ler "em se tratando de paisagem, ainda que possua uma forma material, ela tende ao espiritual".

(3) Tal elaboração, com paralelo na forma de escrever, na cerimônia do chá, enfim, na cultura oriental, revela uma elaboração ao mesmo tempo sensível e protocolar, organizando a relação com a natureza, a sensibilidade e as práticas sociais que as fazem convenientes ou não em cada caso.

(4) BERQUE (disponível em http://wwwsoc.nii.ac.jp/paj2/abstract.html) define essa operação como trajectivite, termo que utiliza desde 1985. Utilizando juntamente com milieux a palavra japonesa fuudo (風土, formada pelos kanjis de vento e terra, indica o aspecto de um espaço, as condições que formam a identidade natural de um local, sendo também a tradição do local), coloca que a relação da sociedade com o meio não pode ser entendida dentro do dualismo objetivo - subjetivo, mas como uma trajetória (ir e vir).

(5) $O$ trabalho que apresentamos a seguir transcreve e resume partes do artigo Paisagem (revista Paisagem e Ambiente n. 20) de autoria de SANDEVILLE JR., 2006 no prelo.

(6) Na abrangência mais ampla da palavra que inclui a "Idade Moderna" e "Contemporânea", da história universal tradicional.

(7) Prospectus (ação de olhar ao longe, vista ao longe, perspectiva, lugar elevado, aspecto exterior, previdência).

(8) Daí a insuficiência das abordagens exclusivamente analíticas (baseadas na decomposição e catalogação de elementos e em sua padronização, por vezes incluindo o conceito de estrutura morfológica ou tipológica). Também as abordagens sistêmicas, embora mais complexas e dinâmicas, correm o risco de se tornarem insuficientes, na medida em que hierarquizam e objetivam o estudo da paisagem (não raro influenciadas por um forte estruturalismo), deixando em um pano de fundo o campo de conflitos que a constitui como tal e como história. Assim, embora possamos colher contribuições importantes de abordagens desse tipo, sobretudo da sistêmica, fica faltando uma abordagem de síntese, mais próxima do que "seja" a paisagem.

(9) Estamos banindo, neste texto, a visão/representação paisagística da paisagem como cena ou pintura, pelas razões já expostas. Tal abordagem tem sua validade como discussão do imaginário sobre a paisagem, mas a paisagem, como tal, não pode ser definida pela mediação da pintura, que é outra coisa. Enfim, tratamos da paisagem como espaço. Entender a paisagem em sua concretude é entendê-la como resultante da ação histórica dos homens em interação com a natureza, ou seja, como conformação em câmbio de processos naturais e humanos num sítio (lugar, região). É, portanto, um termo complexo, a implicar em sínteses diversas, posto que a realidade designada é complexa e interativa. 
(10) "as paineiras [árvore de algodão]/ no tempo de florada/ são idênticas/ às cerejeiras em flor / na minha terra natal" ("wata no ki no/ hana no sakari wa/ sanagara ni/ kokoku no sakura no/hana wo omowashimu").

\section{Bibliografia}

ASSANO, Hiroshi. Ni-chu-ei Gengo bunka jiten. Ed. Mc Milllan Language House, 2000.

BERQUE, Augustin. La trajectivité des formes urbaines. In: SALGUEIRO, Heliana Angotti. Paisagem e arte: A invenção da natureza, a evolução do olhar. São Paulo: I Colóquio Internacional de História da Arte, 2000.

BERQUE, Augustin. Abstract. The trajectivity of human milieux (fuudo). Disponível em: <http://wwwsoc.nii.ac.jp/paj2/ abstract.html $>$. Acesso em $<10$ abr. 2006>.

CLIFFORD, Derek. Los jardines. História, trazado, arte... Madrid: Instituto de Estudios de Administración Local, 1970.

CUNHA, A. G. de. Dicionário etimológico nova fronteira da língua portuguesa. 2. ed. Rio de Janeiro: Nova Fronteira, 1982.

FERREIRA, A. B. de H. Novo dicionário da língua portuguesa. 1. ed. Rio de Janeiro: Nova Fronteira.

IWANAMI, Kikuji. Tankas de Kikuji Iwanami. São Paulo: Aliança Cultural Brasil-Japão, 1993.

LÉVI-STRAUSS, Claude. Tristes trópicos. Lisboa: Edições 70, 1993.

LONGMAN DICTIONARY OF ENGLISH LANGUAGE AND CULTURE. Edimburgo: Longman, 1998.

MENEZES, Ulpiano Bezerra de. A paisagem como fato cultural. In: YÁZIGI, Eduardo (Org.). Turismo e paisagem. São Paulo: Contexto, 2002.

POLETTE, Marcus. Paisagem: Uma reflexão sobre um amplo conceito. Turismo - Visão e ação, ano 2, n. 3, p. 83-94, 1999.

SANDEVILLE JR., Euler. As sombras da floresta. Vegetação, paisagem e cultura no Brasil. 1999. Tese (Doutorado) - Faculdade de Arquitetura e Urbanismo, Universidade de São Paulo, São Paulo, 1999.

Paisagens e métodos. Algumas contribuições para elaboração de roteiros de estudo da paisagem intraurbana. Paisagens em debate, n. 2. Disponível em: <http://www.usp.br/fau/depprojeto/gdpa/paisagens 2004>.

SCHAMA, Simon. Paisagem e memória. São Paulo: Cia das Letras, 1996.

YAMADA, Katsumi; NISHIOKA, Osamu et al. Kakugawa Daijiguem. 3. ed. Tóquio: Kakugawa Shoten, 1993. 